\title{
A percepção autóctone sobre os ambientes naturais com potencial ecoturístico em Luminárias (MG): dinâmica e consequências
}

\author{
Perception autoctone on natural environments with \\ ecotouristic potential in Luminárias (MG, Brazil): dynamics \\ and consequences
}

\begin{abstract}
Vinícius do Couto Carvalho, Wanderley Jorge da Silveira-Jr, Cléber Rodrigo de Souza, Thallita Mayra Soares Fernandes, Marco Aurélio Leite Fontes
\end{abstract}

RESUMO: O ecoturismo é considerado uma atividade com potencial baixo impacto ambiental, geradora de benefícios sociais e, dependente da existência de atrativos naturais. Mas como os indivíduos autóctones percebem essa atividade e se relacionam com suas áreas naturais? 0 objetivo, neste estudo, foi analisar em que nível os indivíduos autóctones se envolvem com os ambientes naturais com potencial ecoturístico e como os percebem em uma localidade em fase inicial de desenvolvimento de práticas ecoturísticas, e a dinâmica desse envolvimento e percepção, a partir do olhar dos jovens, em dois períodos com intervalo de nove anos. Para isso, utilizou-se da iconografia com apresentação de dez fotografias de ambientes com potencial ecoturístico da localidade de Luminárias, Minas Gerais Brasil, para estudantes do ensino médio, com posterior aplicação de um questionário semiestruturado, nos anos de 2007 e 2016. Empregou-se ainda a técnica de observação participante. Como resultado, os ambientes naturais com potencial ecoturístico foram reconhecidos em diferentes níveis e considerados como de alta atratividade, mas seu uso turístico é de baixo envolvimento com os indivíduos autóctones. Os resultados demonstraram ainda que, na dificuldade de uma mobilização contínua que alcance a população, os ambientes escolares mostram-se como espaços facilitadores para o processo de sensibilização e inserção social no planejamento do ecoturismo.

PALAVRAS-CHAVE: Ecoturismo; Protagonismo Social; Socioambientalismo. 


\section{ABSTRACT}

Ecotourism is considered an activity of low environmental impact that generates social benefits, and obviously depends on the existence of natural attraction. But how do autochthonous individuals perceive this activity, and how they relate themselves to their natural areas? The aim of this study was to analyze in what level native individuals get involved with natural environments with ecotourism potential and how they perceive the development of ecotourism practices in inicial phase, as also the dynamics of this involvement and perception through the young people eyes in two periods with a nine-year interval. In order to do so, it was used iconography with the presentation of ten photographs of environments with ecotourism potential from the locality of Luminárias (MG, Brazil) for high school students, with the subsequent application of a semistructured questionnaire, in the years 2007 and 2016. The participant observation technique was also used. As a result, the natural environments with ecotourism potential were recognized at different levels and considered as high attractiveness however, the touristic use among the autochthonous individuals is still low. The results also demonstrated that, in the difficulty of a continuous mobilization that reaches the population, the school grounds are shown as facilitating spaces for the process of awareness and social insertion in ecotourism planning.

KEYWORDS: Ecotourism; Social Protagonism; Socioenvironmentalism.

\section{Introdução}

O ecoturismo é uma atividade comprometida em gerar um baixo impacto no ambiente natural e na cultura local, ajudando a criar renda e emprego para os habitantes locais (OTHMAN; ANWAR; KIAN, 2010), e ainda proporciona oportunidades que contribuem para que os indivíduos se envolvam por meio da visitação a ambientes naturais e percebam sua importância (RAMOS; OLIVEIRA, 2008). Mas como esses indivíduos percebem a atividade do ecoturismo? Como se relacionam com suas áreas naturais?

A percepção é a organização, identificação e interpretação da informação sensorial para representar e compreender 0 ambiente (SCHACTER; GILBERT; WEGNER, 2011). E os estudos da percepção do ecoturismo se contrapõem à visão determinista, face sua análise sistêmica dos componentes interligados, homem - natureza - cultura, tendo como suporte teórico e filosófico os valores e representações mentais da humanidade, seja do ponto de vista do indivíduo, seja do ponto de vista dos grupos sociais (AMORIM, 1987). Assim, a percepção do ambiente apresenta conjuntos de informações que são vistas e sentidas no envolvimento do homem com o ambiente.

As singularidades ambientais e culturais são condições privilegiadas únicas, onde os atributos de um lugar devem ser entendidos pela população e apoiados pelo poder público e iniciativa privada na estruturação ecoturística (VIOLIN; ALVES, 2017; SIMÕES, 2013; MARUJO; SANTOS, 2012; VARGAS, 1998), pois, nem o espaço natural nem a história que um 
lugar pode contar, podem ser duplicados. E, no planejamento territorial para o ecoturismo espera-se que a participação efetiva da comunidade confira credibilidade ao processo, interatividade nas manifestações do homem em seu ambiente e fidelidade na paisagem vivida e construída.

A percepção e as pesquisas sobre ecoturismo variam, enquanto alguns estudos exploram o papel $e$ os determinantes da percepção/preocupação ambiental, definidos como a forma que um indivíduo percebe ou avalia questões ambientais (KEMPTON; BOSTER; HARTLEY, 1995), outros investigam principalmente os fatores sociodemográficos, culturais e geográficos associados à preocupação e experiência direta de degradação ambiental (HUNTER; STRIFE; TWINE, 2010).

Assim, o presente estudo teve por objetivo, analisar em que nível os indivíduos autóctones se envolvem com os ambientes naturais com potencial ecoturístico e como os percebem em uma localidade em fase inicial de desenvolvimento de práticas ecoturísticas, e a dinâmica desse envolvimento e percepção, a partir do olhar dos jovens, em dois períodos com intervalo de nove anos.

Compreendendo que os valores e as percepções ambientais são precursores significativos para o comportamento ambiental (PAUW; PETEGEM, 2011), e a presença de ambientes naturais com interesse para visitação ecoturística, como apresentado pelo município de Luminárias, permite o desenvolvimento de estudos que caracterizem os níveis de envolvimento e percepções de questões ligadas aos ambientes naturais, o que favorece a implementação de ações destinadas à efetiva participação das pessoas em atividades ecoturísticas, a realização deste estudo se justifica.

\section{Material e métodos}

\section{Área de Estudo}

O estudo foi realizado no município de Luminárias, Minas Gerais Brasil, escolhido por apresentar práticas ecoturísticas em fase inicial de desenvolvimento. O mesmo está situado na macrorregião Sul de Minas Gerais e insere-se em uma região de grande atratividade ecoturística, estando entre municípios de Carrancas e São Thomé das Letras que apresentam alta demanda pela atividade supracitada. Devido à sua localização e características naturais, Luminárias encontra-se inserida no Circuito Turístico Vale Verde e Quedas D'água, juntamente com os municípios de Bom Sucesso, Coqueiral, ljaci, Ingaí, Itumirim, Lavras, Nepomuceno, Perdões, São Bento Abade, São Thomé das Letras, Três Pontas e Varginha (SETUR, 2015).

Luminárias possui 5.572 habitantes (IBGE, 2017), dos quais 4.166 residem na área urbana, representando $75 \%$ da população total. As atividades econômicas importantes, tanto na participação do PIB municipal quanto no fornecimento de empregos formais, são a agropecuária e a extração mineral de pedras decorativas, enquanto o ecoturismo e o turismo 
de aventura ainda se encontram em estágio incipiente de desenvolvimento (FIGUEIREDO et al., 2011).

A cidade está a $943 \mathrm{~m}$ de altitude, tendo o ponto mais alto do município a $1.444 \mathrm{~m}$ de altitude. É rodeada por serras e escarpas, onde se encontram cachoeiras de até $30 \mathrm{~m}$ de altura, cavernas, lagos, rios que se afunilam e serpenteiam entre as pedras, além de possuir importante patrimônio histórico-cultural e gastronomia peculiar (CARVALHO; SILVA; OLIVEIRA, 2007). Sua extensão territorial é de $498 \mathrm{~km}^{2}$ e está à $303 \mathrm{~km}$ de Belo Horizonte, 388 km de São Paulo e 36 km de Lavras.

O clima é tropical de altitude (Cwb de Köppen), com uma precipitação anual de $1.594 \mathrm{~mm}$, enquanto a temperatura média anual equivale a $17,8^{\circ} \mathrm{C}$ (ALVARES et al., 2013). Sua vegetação predominante são as Florestas Estacionais Semideciduais (RODRIGUES et al., 2007) e as formações campestres e savânicas naturais que se encontram como manchas localizadas nas porções íngremes ou de elevada altitude das serras, preservadas devido às dificuldades de acesso, contudo, o município não apresenta nenhuma área protegida com status de unidade de conservação legalmente instituída, sendo, todas as áreas selecionados para o estudo, situadas em áreas privadas, nas quais a gestão e controle, quando ocorrem, são realizadas pelos proprietários.

\section{Coleta de dados}

Utilizou-se da iconografia (apresentação de imagens) e do método de aplicação de questionário semiestruturado, a fim de verificar o nível de envolvimento e as percepções acerca de ambientes naturais com potencial ecoturístico. Neste estudo, considerou-se com potencial ecoturístico, dez ambientes naturais que possuem atrativos, em que a atividade turística já se desenvolve, porém de forma incipiente. A escolha destas áreas se deu por levantamento preliminar realizado por meio de visitas ao município, que antecederam a aplicação do questionário, nas quais foram identificadas junto aos proprietários de pousadas e guias turísticos locais sob o seguinte questionamento: quais atrativos naturais do município são mais visitados pelos turistas? Após a identificação dos locais, eles foram visitados, e seus principais atrativos fotografados e registrados para realização da avaliação.

A pesquisa foi executada em dois anos distintos, 2007 e 2016, visando assim verificar também as mudanças no envolvimento e percepções nos dois períodos. Os questionários foram aplicados a um público amostral composto por estudantes das turmas do ensino médio da Escola Estadual Professor Fábregas, a fim de se obter uma expressiva resposta de indivíduos com vínculos e formação de identidade local. Para tanto, em ambos os anos da realização do estudo, as mesmas imagens foram apresentadas, assim como os mesmos questionários aplicados.

Utilizou-se do anfiteatro da escola para que os estudantes das turmas do ensino médio fossem acomodados e orientados quanto aos propósitos da pesquisa com posterior distribuição e aplicação dos questionários. Para que fossem respondidas as perguntas do questionário, apresentaram-se por 
meio de equipamento de projeção visual, dez imagens fotográficas referentes à ambientes naturais selecionados. As imagens foram apresentadas sequencialmente, onde cada uma ficou exposta a visualização dos participantes durante o tempo necessário para que todos respondessem as questões apresentadas no questionário semiestruturado. Os ambientes selecionados (Quadro 1) contemplaram locais em diferentes distâncias da área urbana.

Quadro 1: Locais selecionadas para estudo do nível de envolvimento e percepção de ambientes naturais de potencial ecoturístico em Luminárias (MG, Brasil).

Chart 1: Places selected to study the level of involvement and perception of natural environments of ecotourism potential in Luminárias (MG, Brazil).

\begin{tabular}{|c|c|c|}
\hline $\begin{array}{l}\text { Ambiente de } \\
\text { potencial } \\
\text { ecoturístico }\end{array}$ & Descrição do ambiente & $\begin{array}{l}\text { Distancia da } \\
\text { área urbana } \\
\quad(\mathrm{km})\end{array}$ \\
\hline $\begin{array}{l}1 \text { - Ribeirão da } \\
\text { Ponte (RP) }\end{array}$ & $\begin{array}{c}\text { Pequena corredeira com um grande poço para banho. } \\
\text { Encontra-se à margem da estrada de ligação entre } \\
\text { Luminárias e Carrancas. }\end{array}$ & 3 \\
\hline $\begin{array}{l}2 \text { - Portal de } \\
\text { Pedra (PP) }\end{array}$ & $\begin{array}{l}\text { Formação rochosa natural com aproximadamente quatro } \\
\text { metros de altura, formada por duas colunas sustentando } \\
\text { um bloco. A formação foi destruída por intempéries no } \\
\text { ano 2000, restando apenas uma coluna inteira e parte de } \\
\text { outra, não mais formando um portal. }\end{array}$ & $\begin{array}{l}3 \text { (atualmente } \\
\text { inexistente) }\end{array}$ \\
\hline $\begin{array}{l}3 \text { - Poço do } \\
\text { Moinho (PM) }\end{array}$ & $\begin{array}{c}\text { Corredeira com pequeno poço para banho e que se } \\
\text { encontra à margem da estrada de ligação entre } \\
\text { Luminárias e Carrancas. }\end{array}$ & 1 \\
\hline $\begin{array}{l}4 \text { - Pico do } \\
\text { Cruzeiro (PC) }\end{array}$ & $\begin{array}{c}\text { Formação que lembra uma pequena chapada e que se } \\
\text { encontra na estrada de acesso para a Cachoeira da } \\
\text { Serra Grande. }\end{array}$ & 10 \\
\hline $\begin{array}{l}5 \text { - Cachoeira } \\
\text { da Serra } \\
\text { Grande (CS) }\end{array}$ & $\begin{array}{l}\text { Queda d'água de aproximadamente dez metros de altura } \\
\text { com poço para banho. }\end{array}$ & 14 \\
\hline $\begin{array}{l}6 \text { - Cânion do } \\
\text { Inferno }(\mathrm{Cl})\end{array}$ & $\begin{array}{l}\text { Afunilamento natural do Rio Ingaí, com paredões } \\
\text { rochosos laterais de aproximadamente } 15 \text { metros de } \\
\text { altura. }\end{array}$ & 13 \\
\hline $\begin{array}{l}7 \text { - Caverna da } \\
\text { Serra Grande } \\
\text { (CVS) }\end{array}$ & $\begin{array}{l}\text { Gruta de formação quartzítica, com } 230 \text { metros de } \\
\text { comprimento. }\end{array}$ & 14 \\
\hline $\begin{array}{l}8 \text { - Cachoeira } \\
\text { da Pedra } \\
\text { Furada (PF) }\end{array}$ & $\begin{array}{c}\text { Queda d'água de cinco metros de altura que passa por } \\
\text { uma cavidade natural formada pela força das águas na } \\
\text { rocha, possuindo dois poços para banho. }\end{array}$ & 12 \\
\hline $\begin{array}{l}9 \text { - Cachoeira } \\
\text { do Mandembe } \\
(\mathrm{CM})\end{array}$ & $\begin{array}{c}\text { Queda d'água que se destaca em um complexo de três } \\
\text { cachoeiras, por sua água cristalina e pela piscina natural } \\
\text { que forma por entre suas pedras. }\end{array}$ & 7 \\
\hline $\begin{array}{l}10 \text { - Cachoeira } \\
\text { da Nêga }(\mathrm{CN})\end{array}$ & $\begin{array}{l}\text { Queda d'água de aproximadamente seis metros de } \\
\text { altura localizada no interior de uma mata fechada. }\end{array}$ & 5 \\
\hline
\end{tabular}

Fonte: Elaborado pelos autores (2018).

Source: Elaborated by the authors (2018).

O questionário foi composto de questões relativas ao perfil dos entrevistados (idade, gênero e moradia em área urbana ou rural) e de perguntas referentes às variáveis de envolvimento e percepção dos 
ambientes. As questões apresentadas foram: 1- Você reconhece este local? 2- Qual o nome deste local? 3- Quantas vezes você já foi a este local? 4Você considera que este local é um atrativo ecoturístico? 5- Este local é bem conservado? 6- Você conhece outro local interessante para visitação ecoturística? 7- O que você acha da prática do ecoturismo no seu município?

Empregou-se ainda da técnica de observação participante (MINAYO; DESLANDES; GOMES, 2016), realizada com o contato junto à comunidade, em visitações aos atrativos naturais com potencial ecoturístico e em conversas com responsáveis por estruturas administrativas do poder público local e integrantes da comunidade em geral, com a finalidade de obter maiores informações que corroborassem para compreensão do contexto local.

\section{Análise de dados}

Para se avaliar o envolvimento com os ambientes naturais com potencial ecoturístico e a percepção sobre os mesmos, foi realizada uma Análise de Componentes Principais - PCA (JOLLIFFE; CADIMA, 2016), a partir das questões apresentadas nos questionários como variáveis de análise. Avaliou-se como os ambientes se relacionaram, ou seja, como se diferenciaram ou se assemelharam entre si de acordo com as respostas, e as possíveis modificações dessas similaridades (ou dissimilaridades) no tempo. A análise de variação temporal de cada ambiente foi realizada por meio da ordenação por Procrustes (MARDIA; KENT; BIBBY, 1979) com o objetivo de sintetizar as mudanças nas percepções relativas a cada ambiente de potencial ecoturístico. Para isso, foi utilizada a distância euclidiana como medida de distância e o Escalonamento Multidimensional Não Métrico - NMDS (MINCHIN, 1987) como método de ordenação multivariada. Assim, avaliou-se a variação temporal dos ambientes, podendo ser visualizada a partir do comprimento modular dos vetores. As análises foram realizadas no programa $R$ Studio version 3.3.1 (2016) utilizando o pacote Vegan (OKSANEN et al., 2017). Os dados foram ainda analisados quanto ao perfil dos entrevistados e os valores percentuais relativos a todas variáveis isoladamente, a fim de esclarecer o nível de envolvimento e as percepções do público amostral sobre cada ambiente separadamente, bem como as variações ocorridas nos dois períodos amostrados.

\section{Resultados}

No ano de 2007 a amostragem foi de 72 entrevistados. Destes, 23\% eram do gênero masculino e 77\% feminino. Quanto à moradia, constatou-se que a maioria (79\%) morava na zona urbana da cidade e o restante na zona rural. Em 2016, 149 entrevistados participaram da pesquisa, sendo $38 \%$ do gênero masculino e $62 \%$ feminino e para $85 \%$ a zona urbana era a área de moradia. Em ambos os anos a faixa etária do público amostral foi de 15 a 18 anos. 
A PCA, para os dados de 2007 (Figura 1-A), ordenou os ambientes com potencial ecoturístico principalmente em relação ao eixo 1, apresentando pontos à esquerda associados à elevado reconhecimento, acerto do nome atribuído ao ambiente e frequência de visitação, sendo estes, RP, PM e PP; e um agregado a direita relacionado ao baixo reconhecimento e baixa visitação para $\mathrm{CM}, \mathrm{CVS}, \mathrm{Cl}, \mathrm{CN}$ e PF, tendo ainda ambientes relacionados à elevada conservação e indicação errônea do nome, como CS e PC. Em 2016 (Figura1-B) houve alterações nas posições relativas de alguns ambientes e nas suas relações com as variáveis de percepção. No eixo 1 formou-se um gradiente de pontos em função do reconhecimento, acerto e frequência de visitação, que foi do PM (mais reconhecido, mais apontado corretamente e mais visitado) à CN (menos reconhecida e pouco visitada). No eixo 2 ocorreu uma separação em função da atratividade, conservação e frequência de visitação, formando um agregado superior positivamente correlacionado com PC, CS, PF e CM e um agregado inferior com CN, CVS, Cl, PP, PM e RP.

Os resultados demonstraram que o reconhecimento dos ambientes, a indicação correta de seu nome, sua atratividade e estado de conservação estão diretamente ligados às frequências de visitação realizada em cada um dos ambientes analisados.

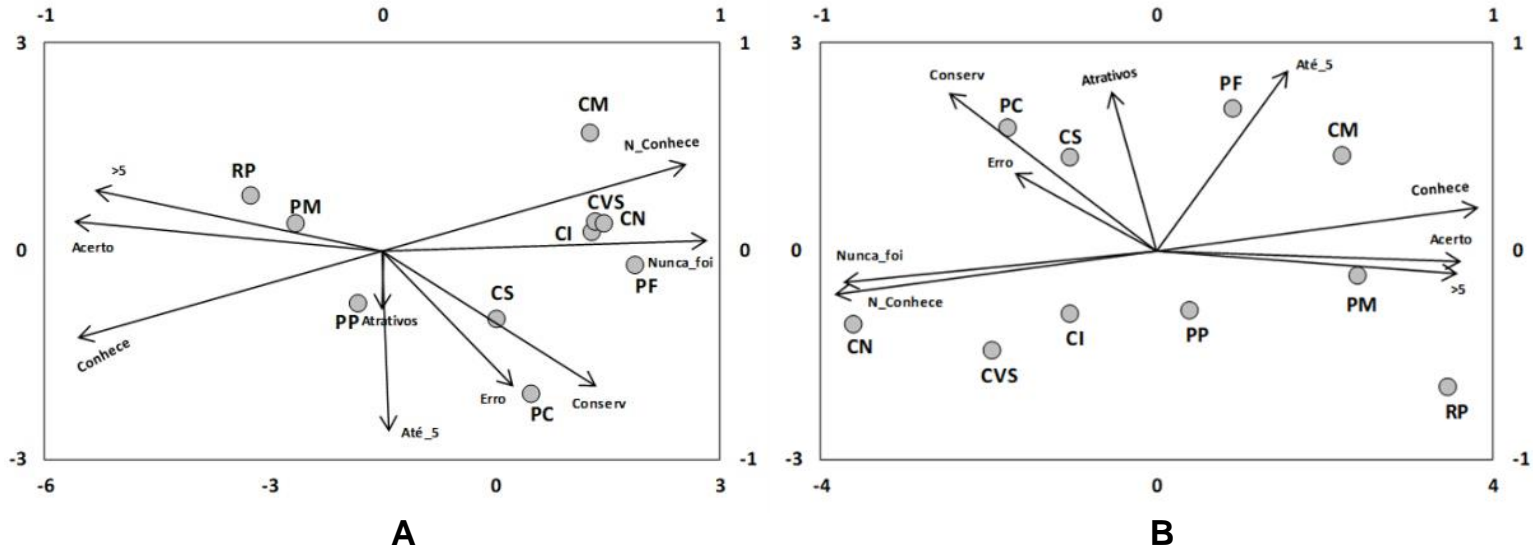

Figura 1: Análise de Componentes Principais (PCA) das variáveis dos anos de (A) 2007 e (B) 2016, sobre o nível de envolvimento e percepção de ambientes naturais de potencial ecoturístico em Luminárias (MG, Brasil).

Figure 1: Principal Component Analysis (PCA) of the variables from (A) 2007 and (B) 2016, on the level of involvement and perception of natural environments of ecotourism potential in Luminárias (MG, Brazil).

Fonte: Elaborado pelos autores (2018).

Source: Elaborated by the authors (2018).

Nota: Visitado mais que cinco vezes $(>5)$, Indicação correta do nome atribuído ao atrativo (Acerto), Reconhece o atrativo (Conhece), Visitado até cinco vezes (Até_5), Indicação errônea do nome atribuído ao atrativo (Erro), Atratividade do ambiente (Atrativos), Nível de conservação (Conserv), Nunca visitou o atrativo (Nunca_foi), Não reconhece 0 atrativo (N_conhece), Ribeirão da Ponte (RP), Portal de Pedra (PP), Poço do Moinho (PM), Pico do Cruzeiro (PC), Cachoeira da Serra Grande (CS), Cânion do Inferno (CI), Caverna da Serra Grande (CVS), Cachoeira da Pedra Furada (PF), Cachoeira do Mandembe (CM) e Cachoeira da Nêga (CN). 
Com o passar dos anos, os ambientes que mais modificaram suas posições foram CM, que passou a ser muito reconhecida e visitada; e PF, que se tornou mais frequentemente visitada, porém ambos menos associados à conservação em 2016. Os resultados apresentados no diagrama obtido na ordenação por Procrustes (Figura 2-A) e no tamanho relativo dos vetores modulares temporais de cada ambiente com potencial ecoturístico (Figura 2-B) reforçam os resultados apresentados na PCA com os ambientes CM e PF acrescidos do PP como os de maiores modificações. Os ambientes PP e CM apresentaram ainda direções opostas de variação se modificando para sentidos opostos quanto às variáveis, tendo como mais relevante a diferença nas frequências de visitação. A qual apresentou PP como ambiente menos visitado, por ser inexistente desde 2000, razão da queda em seu reconhecimento. Porém, o acerto na indicação de seu nome se manteve elevado, demonstrando o seu não esquecimento.

Já, o crescimento expressivo no reconhecimento, indicação assertiva e frequência de visitação da PF e CM em 2016, foi em decorrência das melhorias na estruturação de seus acessos, pela manutenção das estradas de terra, como verificado na observação participante.
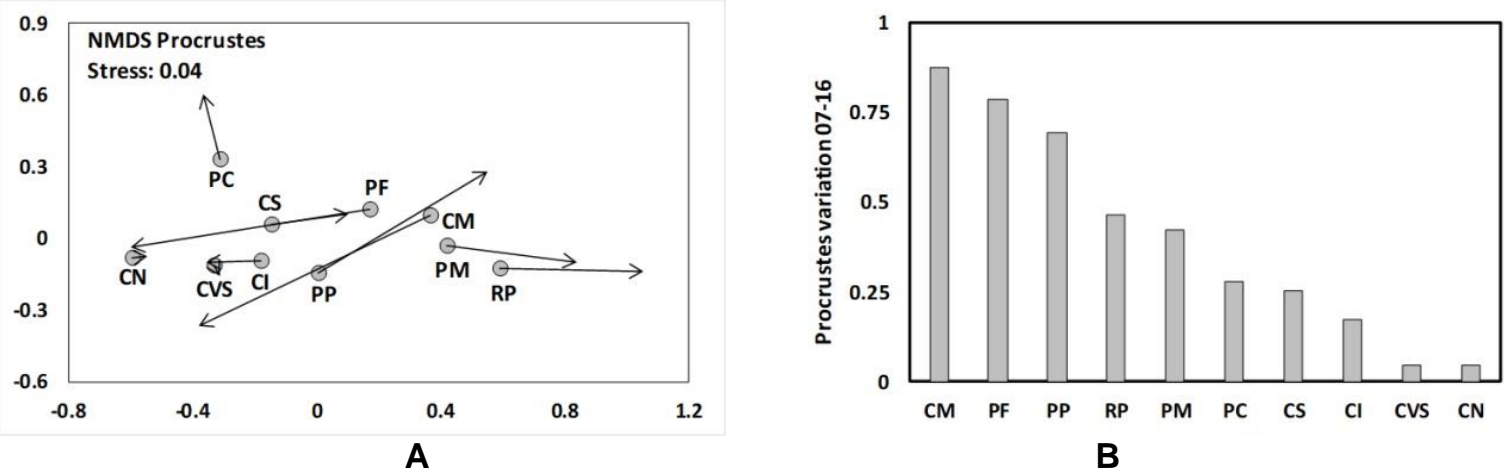

Figura 2: Ordenação por PROCRUSTES, utilizando Escalonamento Multidimensional Não Métrico como método de ordenação $(A)$ e Comprimentos modulares dos vetores de variação temporal de cada ambiente (B), para estudo do nível de envolvimento e percepção de ambientes naturais de potencial ecoturístico em Luminárias (MG, Brasil).

Figure 2: Sorting by PROCRUSTES, using Non-Metric Multidimensional Scaling as a sorting method $(A)$ and Modular lengths of the temporal variation vectors of each environment $(B)$,

to study the level of involvement and perception of natural environments of ecotourism potential in Luminaires (MG, Brazil).

Fonte: Elaborado pelos autores (2018).

Source: Elaborated by the authors (2018).

Nota: Ribeirão da Ponte (RP), Portal de Pedra (PP), Poço do Moinho (PM), Pico do Cruzeiro (PC), Cachoeira da Serra Grande (CS), Cânion do Inferno (CI), Caverna da Serra Grande (CVS), Cachoeira da Pedra Furada (PF), Cachoeira do Mandembe (CM) e Cachoeira da Nêga (CN). Fonte: Elaborado pelo autor (2018).

Quanto às variáveis analisadas acerca do envolvimento com os ambientes naturais com potencial ecoturístico (reconhecimento, indicação do nome atribuído e frequência de visitação), notou-se que no aspecto de reconhecimento dos ambientes (Figura 3), dentre os dez ambientes pesquisados, em 2007, cinco ambientes (PP; PC; CS; CVS e CN) foram os mais reconhecidos e em 2016 quatro outros se destacaram (RP; Cl; PF e 
$\mathrm{CM}$ ). Contudo, quando comparado o percentual relativo de reconhecimento dos ambientes, superior a $50 \%$ nos dois anos, constatou-se que em 2007 cinco atrativos (RP, PP, PN, PC e CS) foram reconhecidos por mais de $71 \%$ e os cinco demais por menos de $46 \%$. Já em 2016, oito dos atrativos foram reconhecidos por mais de $53 \%$ e os demais por menos de $41 \%$. Os resultados demonstram que ao se considerar um percentual de reconhecimento superior a $50 \%$ dos entrevistados em 2016, os ambientes se tornaram mais reconhecidos, porém com percentual relativo menos expressivo, excetuando-se apenas a PF e a CM.

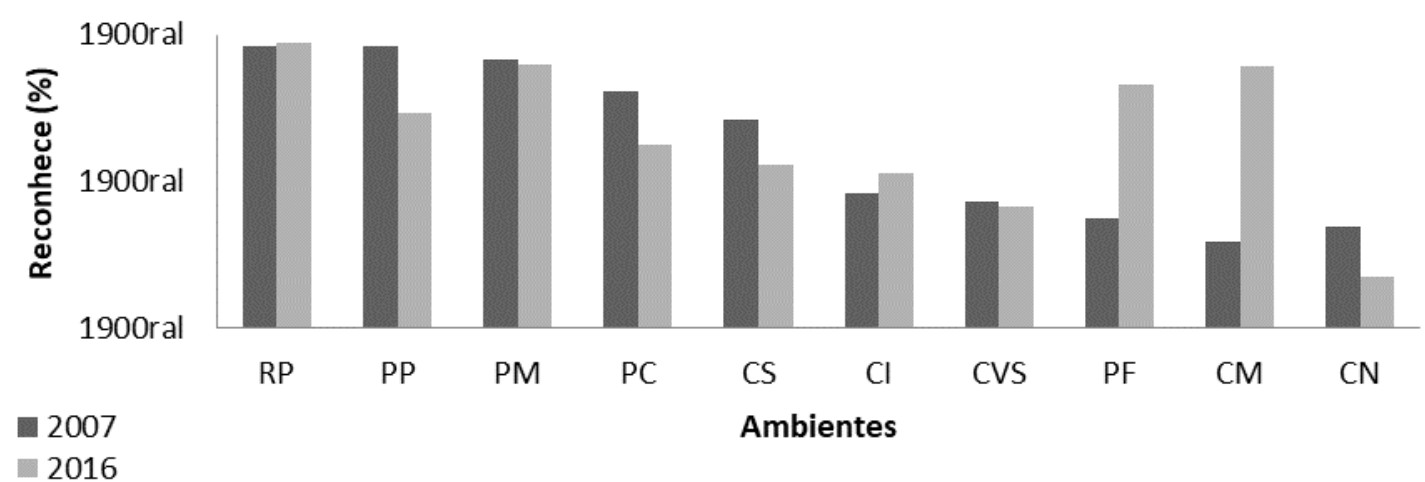

Figura 3: Reconhecimento dos ambientes pelos autóctones para estudo de seu nível de envolvimento com ambientes naturais de potencial ecoturístico em Luminárias (MG, Brasil). Figure 3: Recognition of environments by native people to study their level of involvement with natural environments of ecotourism potential in Luminárias (MG, Brazil).

Fonte: Elaborado pelos autores (2018).

Source: Elaborated by the authors (2018).

Nota: Ribeirão da Ponte (RP), Portal de Pedra (PP), Poço do Moinho (PM), Pico do Cruzeiro (PC), Cachoeira da Serra Grande (CS), Cânion do Inferno (Cl), Caverna da Serra Grande (CVS), Cachoeira da Pedra Furada (PF), Cachoeira do Mandembe (CM) e Cachoeira da Nêga $(\mathrm{CN})$.

Para a indicação do nome atribuído aos ambientes (Figura 4), manteve-se, em ambos os anos analisados, grande percentual de acerto para PP, PM e RP. Notou-se ainda que apresentaram aumento expressivo na indicação correta do nome no ano de 2016: $\mathrm{Cl}$, passando de $21 \%$ para $55 \%$; PF de $3 \%$ para $81 \%$ e CM de $25 \%$ para $87 \%$. Contudo, manteve-se errôneas as indicações do PC (sendo chamado de Serra do Navio) e a não indicação de nome da CN (sem respostas).

As não indicações do nome do ambiente $\mathrm{CN}$ se relacionaram à intenção de não incentivo à visitação no local, pois a mesma é área de capitação de água da cidade. E a indicação errônea do PC ocorreu devido à confusão feita em decorrência de sua localização na Serra de Santo Inácio, conhecida localmente por Serra Grande. Esta área compreende picos e serras de formação rochosa similar, como a da Serra do Navio, a qual tem seu nome regionalmente conhecido, contudo sem visitação, pois está inserida em área particular com exploração minerária de pedras decorativas (quartzito), conforme a observação participante. 


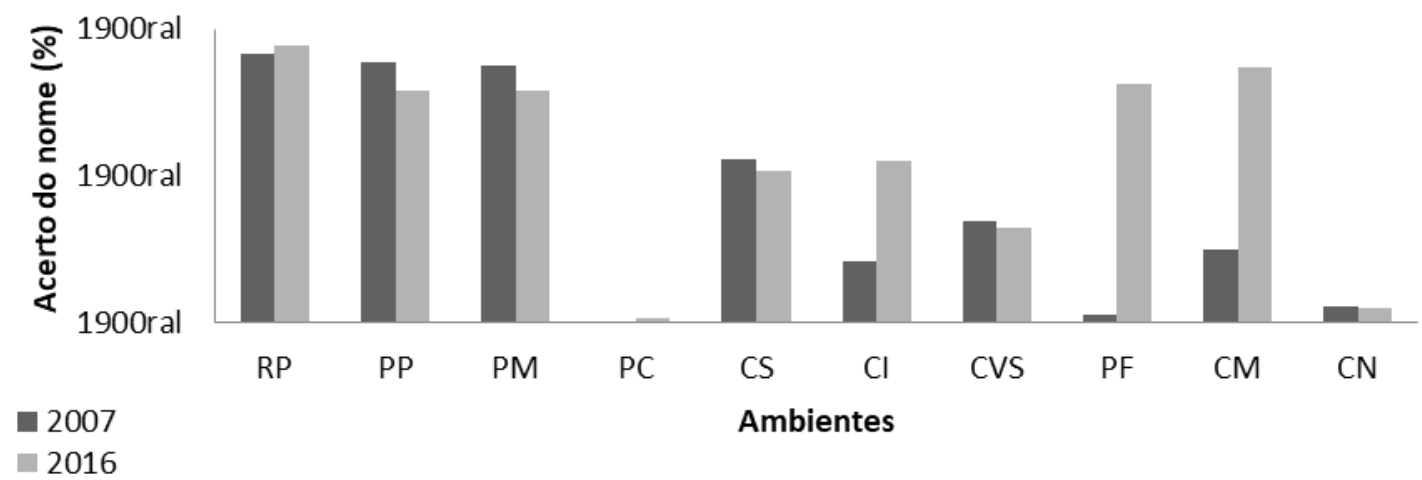

Figura 4: Indicação correta do nome atribuído aos ambientes pelos autóctones para estudo de seu nível de envolvimento com ambientes naturais de potencial ecoturístico em Luminárias (MG, Brasil).

Figure 4: Correct indication of the name attributed to the environments by the natives to study their level of involvement with natural environments of ecotourism potential in Luminárias (MG, Brazil).

Fonte: Elaborado pelos autores (2018).

Source: Elaborated by the authors (2018).

Nota: Ribeirão da Ponte (RP), Portal de Pedra (PP), Poço do Moinho (PM), Pico do Cruzeiro (PC), Cachoeira da Serra Grande (CS), Cânion do Inferno (Cl), Caverna da Serra Grande (CVS), Cachoeira da Pedra Furada (PF), Cachoeira do Mandembe (CM) e Cachoeira da Nêga $(\mathrm{CN})$.

As respostas acerca da frequência de visitação evidenciaram que PC, CS, CI, CVS e CN nunca foram visitados por um percentual igual ou superior a $53 \%$ dos entrevistados em ambos os anos (Figura 5-A). Com o passar dos anos, PP, PC, CS, CI, CVS e CN obtiveram um aumento quanto a não visitação, ressaltando-se que apresentaram aumento considerável neste mesmo aspecto, o PP (de $34 \%$ para $70 \%$ ) e CN (de $59 \%$ para $93 \%$ ). Em relação à visitação em até cinco vezes (Figura $5-\mathrm{B}$ ), nenhum ambiente atingiu um percentual superior aos $39 \%$ do PP em 2007. Porém, PF e PM apresentaram aumento em 2016. Já em relação aos ambientes mais de cinco vezes visitados (Figura 5-C), RP e PM foram os mais citados em ambos os anos, com inclusão da CM em 2016, que passou de $15 \%$ para $49 \%$.

Os resultados demonstraram que um maior envolvimento da comunidade se deu, em ambos os anos analisados, com os ambientes mais próximos da área urbana. Um maior envolvimento com ambientes mais distantes só se deu naqueles que sofreram melhorias estruturais em seus acessos.

Quanto às variáveis de percepção (atratividade, estado de conservação, conhecimento de outros ambientes e entendimento sobre ecoturismo e sua prática), constatou-se que a atratividade dos ambientes com potencial ecoturístico (Figura 6) se mantiveram altas nos dois anos analisados. Porém, em 2016, o percentual relativo a esse aspecto foi inferior para grande parte dos ambientes, excetuando $\mathrm{Cl}$, PF e CM. 
A

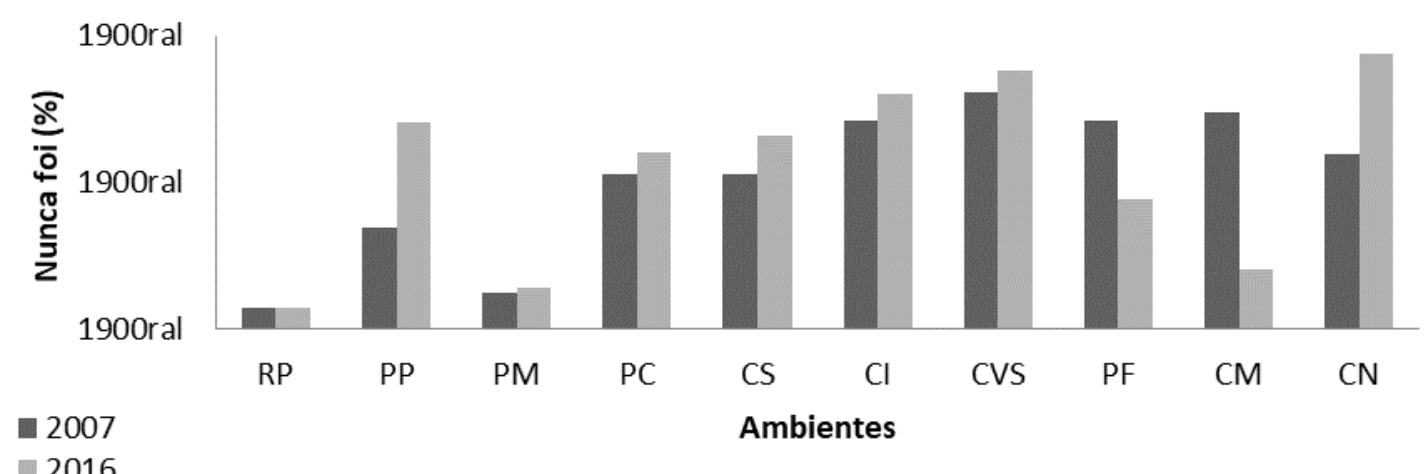

B

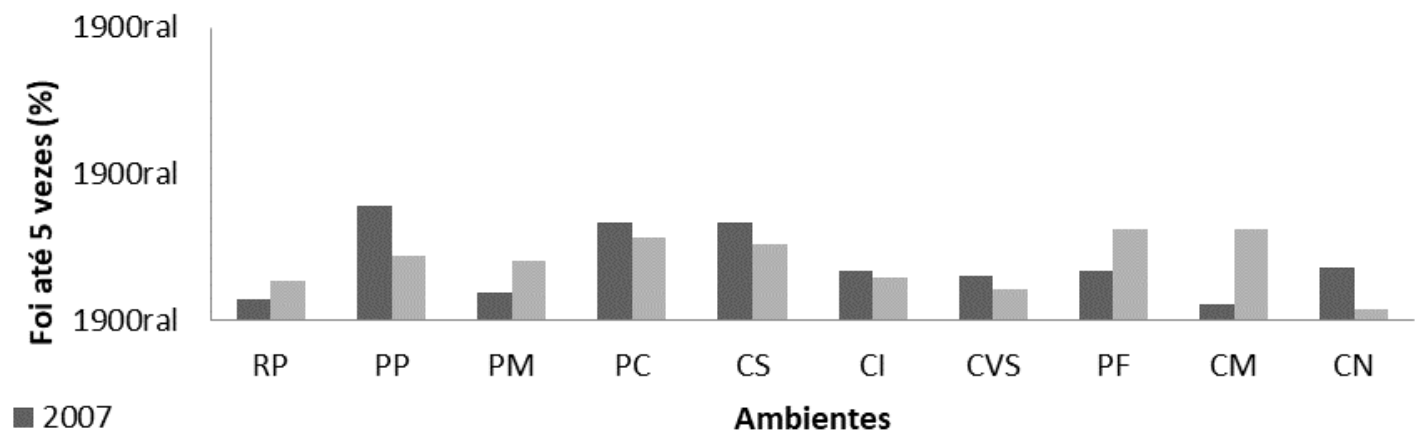

2016

C

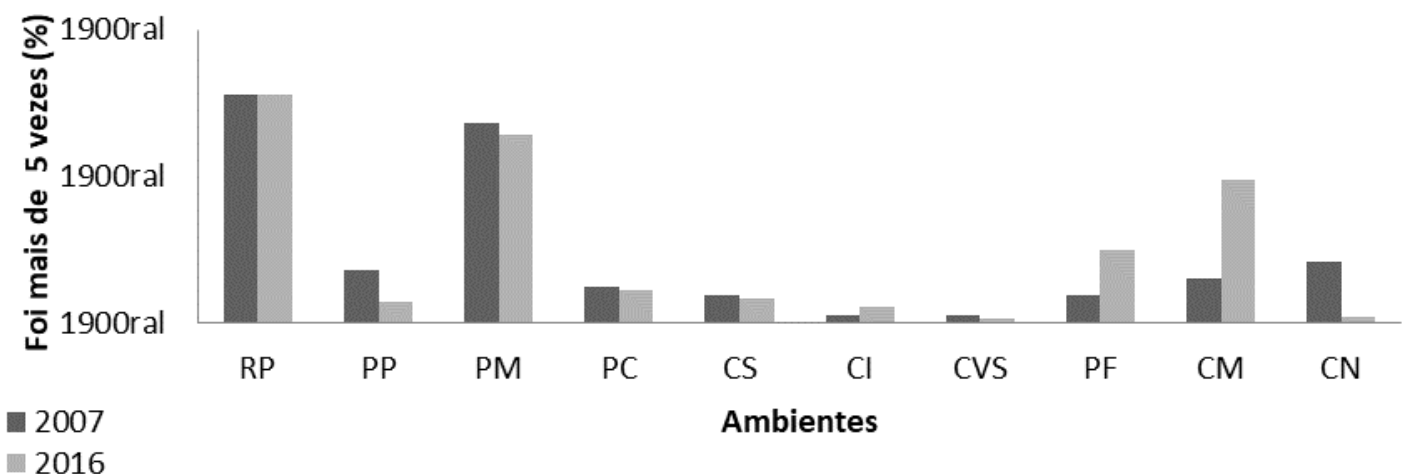

Figura 5: Frequência de visitação pelos autóctones, onde $(A)$ representa nenhuma visitação, (B) de uma e cinco visitas ao local e (C) mais de cinco visitas ao local, para estudo do nível de seu envolvimento com ambientes naturais de potencial ecoturístico em Luminárias (MG, Brasil).

Figure 5: Frequency of visitation by indigenous people, where (A) represents no visitation, (B) one and five visits to the site and (C) more than five visits to the site, to study the level of their involvement with potential natural environments ecotourism in Luminárias (MG, Brazil).

Fonte: Elaborado pelos autores (2018).

Source: Elaborated by the authors (2018).

Nota: Ribeirão da Ponte (RP), Portal de Pedra (PP), Poço do Moinho (PM), Pico do Cruzeiro (PC), Cachoeira da Serra Grande (CS), Cânion do Inferno (Cl), Caverna da Serra Grande (CVS), Cachoeira da Pedra Furada (PF), Cachoeira do Mandembe (CM) e Cachoeira da Nêga (CN). 


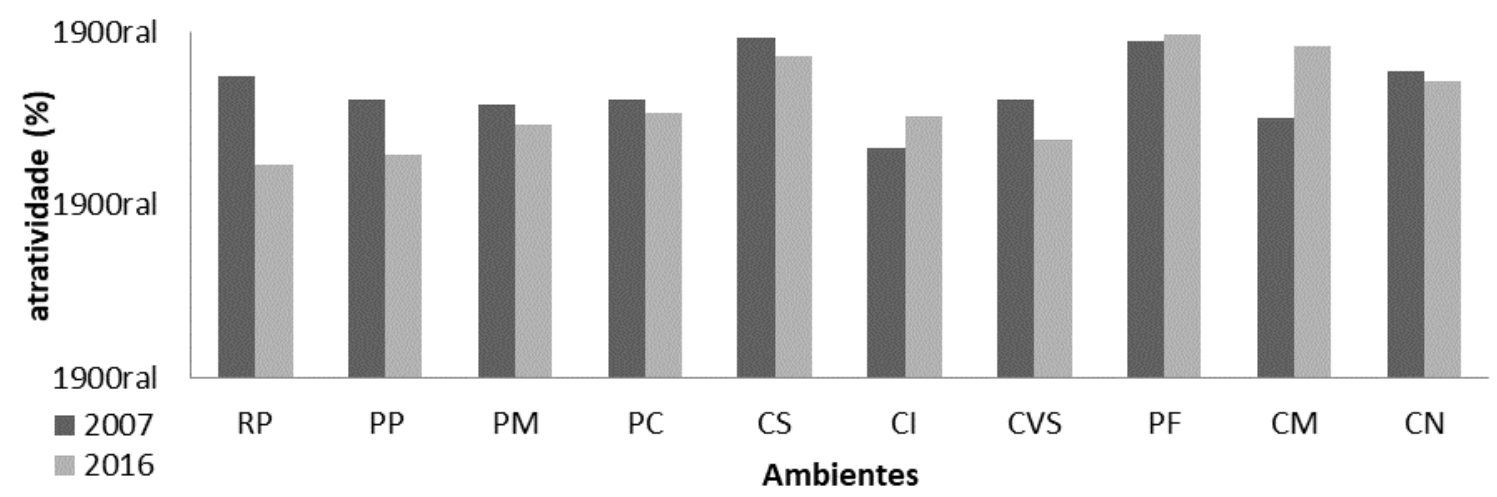

Figura 6: Atratividade dos ambientes naturais de potencial ecoturístico na percepção dos autóctones em Luminárias (MG, Brasil).

Figure 6: Attractiveness of natural environments with ecotourism potential in the perception of indigenous people in Luminárias (MG, Brazil).

Fonte: Elaborado pelos autores (2018).

Source: Elaborated by the authors (2018).

Nota: Ribeirão da Ponte (RP), Portal de Pedra (PP), Poço do Moinho (PM), Pico do Cruzeiro (PC), Cachoeira da Serra Grande (CS), Cânion do Inferno (Cl), Caverna da Serra Grande (CVS), Cachoeira da Pedra Furada (PF), Cachoeira do Mandembe (CM) e Cachoeira da Nêga (CN).

Quanto ao estado de conservação dos ambientes (Figura 7), foi verificado um decréscimo nos níveis, onde apenas a CM apresentou melhoria na conservação (na percepção dos entrevistados) entre os anos de 2007 e 2016; e PM, PC e CN não se alteraram. Os ambientes que sofreram maiores quedas no aspecto conservação foram a CS, passando de $79 \%$ para $68 \%$, Cl de $58 \%$ para $43 \%$, CVS de $60 \%$ para $44 \%$ e PF de $74 \%$ para $66 \%$. Contudo, o ambiente com o menor percentual relacionado à conservação da área foi RP com 13\%.

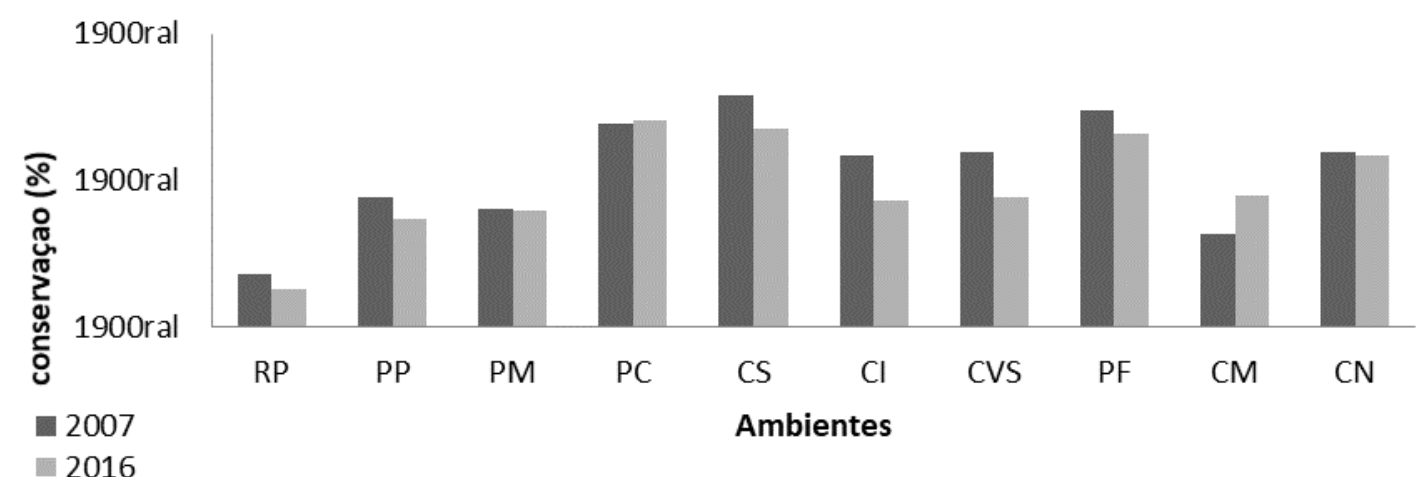

Figura 7: Estado de conservação dos ambientes naturais de potencial ecoturístico na percepção dos autóctones em Luminárias (MG, Brasil).

Figure 7: Conservation status of natural environments with ecotourism potential in the perception of indigenous people in Luminárias (MG, Brazil).

Fonte: Elaborado pelos autores (2018).

Source: Elaborated by the authors (2018).

Nota: Ribeirão da Ponte (RP), Portal de Pedra (PP), Poço do Moinho (PM), Pico do Cruzeiro (PC), Cachoeira da Serra Grande (CS), Cânion do Inferno (Cl), Caverna da Serra Grande (CVS), Cachoeira da Pedra Furada (PF), Cachoeira do Mandembe (CM) e Cachoeira da Nêga (CN). 
Os apontamentos sobre a conservação referiram-se aos ambientes mais próximos à área urbana do município (RP e $\mathrm{PM}$ ) como os menos conservados. Estes, historicamente, são áreas de uso para lazer da comunidade em finais de semana e feriados como carnaval, quando se tem uma visitação em massa e sem conscientização de uso (consumo de bebidas alcoólicas, e alimentos, sons automotivos e lixo espalhado pela área), como pôde ser observado in loco.

Quando questionados se conheciam outros locais interessantes para visitação ecoturística no município (Quadro 2), em 2007 foram citados 11 locais e em 2016 os entrevistados indicaram 22 locais como ambientes com potencial ecoturístico.

Quadro 2: Indicações de ambientes naturais com potencial para o desenvolvimento do ecoturismo em Luminárias (MG, Brasil), a partir da percepção dos estudantes.

Chart 2: Indications of natural environments with potential for the development of ecotourism in Luminárias (MG, Brazil), from the students' perception.

\begin{tabular}{|l|l|}
\hline \multicolumn{1}{|c|}{2007 - 11 locais } & \multicolumn{1}{c|}{2016 - 22 locais } \\
\hline - Cristo (25\%); & - Cristo (17\%); \\
- Cachoeira do Paredão (15\%); & - Poço do Lobo (11\%); \\
- Usina da Fumaça (8\%); & - Usina da Fumaça (9\%); \\
- Água Santa, Serra de Luminárias e & - Cachoeira do Paredão (8\%); \\
Cachoeira da Caverninha (3\% cada); & - Água Santa (4\%); \\
- Escada, Serra da Mamica, Cachoeira & - Serra do Navio, Pico do Gavião e Serra da Mamica \\
do Elói, Escorregador da Serra Grande & (3\% cada); \\
e Cachoeira do Mamono (2\% cada). & - Pico da Asa Delta, Torre, Escada e Cachoeira da \\
& Caverninha (2\% cada); \\
& - Monjolo, Serra de Luminárias, Cachoeira da Esmeralda \\
& e Cachoeira do Lavarejo (1\% cada); \\
& - Salto do Rio Ingaí, Cachoeira do Elói, Escorregador da \\
& Serra Grande, Poço do Mangue, Serra Grande e \\
& Cachoeira do Mamono (percentuais abaixo de 1\% de \\
\hline $33 \%$ não indicaram nenhum outro local & indicação). \\
\hline
\end{tabular}

Fonte: Elaborado pelos autores (2018).

Source: Elaborated by the authors (2018).

Por fim, os resultados demonstraram ainda que em 2007, para $61 \%$ dos entrevistados a prática do ecoturismo foi considerada como positiva para a cidade. Já em 2016, a prática do ecoturismo passa a ser compreendida como positiva para $54 \%$ dos entrevistados.

Com relação aos resultados obtidos da observação participante, poucas intervenções relacionadas ao ecoturismo puderam ser verificadas. Constatou-se o uso tradicional de ambientes mais próximos à área urbana por parte da comunidade em momentos de lazer e as melhorias estruturais dos acessos a ambientes naturais, o que por sinal não foi para atender ou fomentar a visitação, mas sim para manter o trânsito da comunidade rural até a sede do município. As políticas públicas também fazem parte das estruturas que promovem o ecoturismo e, durante o período estudado, pôde se observar apenas duas intervenções, uma em 2008 e outra em 2010, sendo estas a aprovação da Lei 1.098/2008 que regulamentou a atividade de Monitores de Ecoturismo e Condutores Ambientais no município de 
Luminárias e da Lei Ordinária 1.140/2010 sobre nova redação a dispositivos da lei $n^{\circ} 1.028 / 2005$ que "Cria o Conselho Municipal e o Fundo Municipal de Turismo e dá outras providencias" (CAMARA MUNICIPAL DE LUMINÁRIAS, 2017). Contudo, nenhuma destas políticas púbicas foram implementadas, ou outra foi encontrada no período analisado (2007 à 2016), como também nenhum evento de fomento das práticas ecoturísticas foi observado ou consta nos registros municipais.

\section{Discussão}

O ecoturismo é uma ferramenta de conservação que visa construir apoio e elevar a consciência para assuntos importantes de proteção de ambientes naturais, culturais, espirituais, de valores estéticos, recreativos e econômicos (BUSHELL; EAGLES, 2007). Sendo assim, os ambientes com atratividade ecoturística precisam ser reconhecidos localmente e ter as percepções quanto a seus usos pesquisadas, compreendendo seus aspectos ambientais e a sua produção de benefícios para as comunidades locais, a fim de incentivar o envolvimento comunitário e a conservação dos ambientes naturais locais (WIGHT, 2002; KRUGER, 2005).

O estudo de Okello (2003) revelou que a sensibilização da comunidade sobre a conservação da natureza alterou a maioria dos povos ugandeses para a conservação de seus recursos naturais e ajudou a desenvolver o país como destino ecoturístico. Uma vez que as atividades de ecoturismo são fonte de benefícios para as comunidades locais, elas desenvolvem atitudes em relação à conservação de seus recursos naturais e também ajudam a reduzir os impactos negativos sobre o meio ambiente e sua degradação, melhorando o ambiente e a qualidade dos moradores, como já visto em experiências taiwanesas (TSAUR; LIN; LIN, 2006). Contudo, a partir do presente estudo, acredita-se que só esperar que o desenvolvimento da atividade ecoturística promova a compreensão da importância dos ambientes naturais locais pode ser contar com a sorte. É preciso promover espaços públicos de discussão sobre os ambientes naturais locais e a prática de ecoturismo e, para isso, o ambiente escolar se apresenta como oportuno, como aqui demonstrado.

Desta forma, o ecoturismo pode se constituir em uma oportunidade de se promover atitudes de respeito e a favor da conservação da natureza, tendo as escolas como ambientes públicos para promoção de discussões acerca dos ambientes naturais com potencial ecoturístico, a fim de incluir esta temática na formação da identidade local. Observando-se que estas discussões devem ser conduzidas com preparação, sentido, mediação e processos educativos (RAMOS; OLIVEIRA, 2008; PAKARINEN, 2015). Assim, a compreensão da comunidade sobre o ecoturismo e seus ambientes naturais subsidiará sua decisão em fazer uso consciente dos ambientes para lazer e de participar ou não das práticas ecoturísticas desenvolvidas no município (ZHANG; LEI, 2012).

O envolvimento da comunidade com seus ambientes e com as práticas ecoturísticas, promove o reconhecimento e a identificação com os mesmos e, por consequência, uma proximidade e a busca por melhorias. 
Estudos realizados na África demonstraram que a participação comunitária no ecoturismo trouxe benefícios como: aumento da renda, criação de emprego, contribuição para 0 desenvolvimento de infraestruturas e desenvolvimento comunitário; e os benefícios potenciais das empresas de ecoturismo foram proporcionais ao nível de envolvimento da comunidade local, onde quanto maior o nível de envolvimento, maiores os benefícios (MANYARA; JONES, 2007).

A verificação das percepções e do envolvimento com os ambientes naturais de potencial ecoturístico em Luminárias nos dois períodos com um intervalo de nove anos demonstrou uma diminuição quanto ao entendimento dos benefícios ambientais, socioculturais e econômicos propalados pelo mesmo. Assim, a consideração das percepções por parte dos planejadores e gestores deve promover o fomento a espaços de discussão em ambientes escolares e abertos ao público em geral, com foco na participação da comunidade local à frente das atividades ecoturísticas. Por isso, e como um princípio central da definição de ecoturismo, as questões de envolvimento e educação precisam ser abordadas e contempladas em planejamentos e projetos para que se alcance a efetividade nas práticas ecoturísticas locais.

A divulgação dos ambientes naturais de Luminárias, Minas Gerais, de per si, não representa uma estratégia eficiente no planejamento ecoturístico, limita-se à mera informação da existência dos ambientes e não resulta no envolvimento da comunidade. É imprescindível o fomento à interação em momentos de lazer da comunidade em seus ambientes naturais, proporcionando experiências agradáveis fundamentais para o envolvimento com o ecoturismo. Pois, quanto maior for o conhecimento de suas áreas e 0 envolvimento com as mesmas, além da percepção quanto à necessidade de proteção de recursos, os residentes locais se sentirão parte do ambiente e poderão receber uma variedade de benefícios infraestruturais, econômicos e sociais tangíveis ao se tornar comunidades receptoras para ecoturistas, o que os resultados demonstraram não estar acontecendo. Ross e Wall (1999) já alertaram que sem participação local, provavelmente os benefícios deixam de ser da comunidade.

A inexistência de um processo permanente de políticas públicas para - ecoturismo e de órgãos administrativos municipais efetivos de planejamento e fomento às atividades contribui para a diminuição nos níveis de conhecimento e visitação dos ambientes naturais com potencial ecoturístico, como também para a diminuição da compreensão, envolvimento, promoção do ecoturismo e empreendedorismo local. É importante lembrar que, conforme Ramos e Oliveira (2008), mesmo durante as etapas do planejamento ecoturístico, a percepção ambiental da população autóctone e sua relação com o meio devem ser substancialmente consideradas para que as verticalidades adjacentes aos empreendimentos turísticos não se sobreponham às relações de horizontalidade da comunidade local.

Sabe-se de muitos casos onde as comunidades foram excluídas, marginalizadas ou tiveram acesso restrito aos recursos naturais, devido a empreendimentos de turismo. Como já apresentado por Duffy (2002), em 
alguns casos, a expansão do turismo reduz a oportunidade para que as pessoas locais participem do seu desenvolvimento, exceto como funcionários comuns. $O$ mesmo autor ainda alerta que muitas outras críticas ao turismo já foram vistas no ecoturismo como recriação de padrões coloniais de comportamento e exploração, não conseguindo investimentos significativos para economias locais e exclusão social da população local. Como já ressaltado por Pires e Alcantarino (2008), a conduta da comunidade local frente à implementação da atividade ecoturística, algo esquecido por alguns técnicos, é fator preponderante à garantia de sua sustentabilidade como atividade em um dado local.

Acredita-se, como outros autores (DVORAK; BROOKS, 2013; POMERANZ; NEEDHAM; KRUGER, 2013; DVORAK; BORRIE; WATSON, 2013), que o reconhecimento das relações ocorridas com o passar dos anos e os significados do lugar podem fortalecer experiências e compromissos com o local, e que o entendimento das relações sociais, dos processos políticos, das atividades socioeconômicas e dos significados da atividade, são altamente aplicáveis ao planejamento, gestão e conservação das áreas naturais, especialmente em planejamento participativo (MANZO; PERKINS, 2006; HOŔELLI, 2002) e gestão colaborativa (SELIN, 2004; GRAY, 1985).

Primar pela implementação de políticas públicas de ecoturismo que contemplem a inserção da temática no dia-a-dia das comunidades contribui para a formação da identidade local, promove o empoderamento das comunidades locais, a conservação dos ambientes naturais e culturais e as práticas ecoturísticas sustentáveis. Mas, o dia-a-dia das pessoas pode ser bastante complicado de se alcançar, dada a sua complexidade natural, seja na variedade de ocupações profissionais no tempo diário ou até mesmo nas divisões de classes sociais. Neste contexto, os ambientes escolares mostram-se como espaços férteis para o processo de conscientização e inserção, como tem já sido para tantos outros temas que não o ecoturismo, pois "[...] não há prática educativa que não se direcione para um certo objetivo, que não envolva um certo sonho, uma certa utopia" (FREIRE, 1994, p. 163). A politicidade da educação torna-se evidente na permanente reflexão referente ao "o que fazer", "para que fazer", "quando" e "para quem fazer", e assim, os ambientes escolares se mostram como facilitadores da mobilização para um planejamento ecoturístico, respeitando-se todas as suas premissas.

\section{Conclusão}

Ao analisar os ambientes naturais com potencial ecoturístico em Luminárias, localidade em fase inicial de desenvolvimento de práticas ecoturísticas, conclui-se que estes são reconhecidos pelos moradores em diferentes níveis e considerados como de alta atratividade. Contudo, seu uso recreativo é de baixo envolvimento com os indivíduos autóctones, sobretudo os localizados mais distantes, ainda que melhorias das estradas de acesso tenham sido realizadas pelo poder público. Todavia, os ambientes naturais mais próximos são os menos conservados, pois abrigam um número maior de visitantes locais, que participam sem os cuidados necessários, previstos no ecoturismo. Neste sentido, recomenda-se que políticas públicas sejam 
elaboradas e implementadas a fim de promover o respeito aos ambientes naturais com potencial ecoturístico, mas também a inserção participativa da atividade ecoturística no município, promovendo o protagonismo e empoderamento da comunidade local.

Todavia, o fato de todas as áreas objetos deste estudo estarem localizadas em propriedade privadas dificulta a participação do poder público nas ações de fiscalização e sensibilização, sobretudo naquelas que sofrem com o turismo desordenado. Neste caso, a sensibilização a respeito da conservação das áreas naturais deve estender-se aos proprietários das áreas visitadas. Constatou-se que na dificuldade de uma mobilização contínua que alcance a população, os ambientes escolares mostram-se como espaços facilitadores para o processo de sensibilização e inserção social no planejamento ecoturístico.

Conclui-se ainda, que a replicação dos métodos deste estudo se apresenta como ferramenta estratégica para monitoramento do nível de envolvimento e percepções da comunidade local acerca do ecoturismo em suas áreas naturais.

\section{Referências}

ALVARES, C. A., STAPE, J. L., SENTELHAS, P. C., GONÇALVES, J. L. M.; SPAROVEK, $G$. Köppen's climate classification map for Brazil. MeteorologischeZeitschrift, v. 22, n. 6, p. 711-728, 2013.

AMORIM, F.O.B. O contexto teórico do desenvolvimento dos estudos humanísticos e perceptivos na Geografia. In: AMORIM, F.O.B.; CARTER, H.; KOHLSDORF, M.E. Percepção Ambiental: contexto teórico e aplicações ao tema urbano, Instituto de Geociências - UFMG, Belo Horizonte, publicação especial n. 5, 1987.

BUSHELL, R.; EAGLES, P. F. J. Tourism and Protected Areas: Benefits Beyond Boundaries. The 5th World Parks Congress, CAB International 200, UK, 2007.

CAMARA MUNICIPAL DE LUMINÁRIAS. Legislação Municipal. Disponível em:<www.luminarias.cam.gov.br/pagina/6496/2017> . 25/11/2017.

Acessado em:

CARVALHO, V. C; SILVA, M. A. C.; OLIVEIRA, D. V. Potencialidades espeleoturísticas da área cárstica do município de Luminárias (MG, Brasil), Pasos, v. 5, n. 3, p.383-390, 2007.

DUFFY, R. A Trip Too Far: Ecotourism. Politics and Exploitation. Detroit, Earthscan, v. 1, p. 210, 2002.

DVORAK, R. G.; BROOKS, J. J.More connection and less prediction please: applying a relationship focus in protected area planning and management. Journal of Park and Recreation Administration. v.31, p. 5-22, 2013.

DVORAK, R. G.; BORRIE, W. T.; WATSON A. E. Personal wilderness relationships: building on a transactional approach. Environmental Management, v. 52, p.1518-1532, 2013.

FIGUEIREDO, L. A. V.; SOUZA, L. D.; CARVALHO, A. M.; LIMA, J. N.; MIRANDA, F. D. lluminando Luminárias (MG): práticas espeleoturísticas e de 
Educação Ambiental integrando aventura, natureza e cultura. Anais do VIII Congresso Nacional de Ecoturismo e do IV Encontro Interdisciplinar de Ecoturismo em Unidades de Conservação. Revista Brasileira de Ecoturismo, São Paulo, v.4, n.4, p. 563, 2011.

FREIRE, P. Cartas a Cristina. Rio de Janeiro: Paz e Terra, 1994.

GRAY, B. Conditions facilitating interorganizational collaboration. Human Relations, v. 38, n.10, p. 911-936, 1985.

HOREELLI, L. A methodology of participatory planning. In: BECHTEL. R. B.; CHURCHMAN, A. (Eds.), Handbook of environmental psychology (pp. 607628). New York, NY: Wiley. 2002.

HUNTER, L. M.; STRIFE, S.; TWINE, W. Environmental perceptions of rural South African residents: The complex nature of environmental concern. Society and Natural Resource, v.23, p. 252-541, 2010.

IBGE. Ministério do Planejamento, Orçamento e Gestão. Instituto Brasileiro de Geografia e Estatística. Censo Demográfico 2015. 2017. Disponível em: $<$ http://www.cidades.ibge.gov.br/xtras/perfil.php?lang=\&codmun=313870\&searc $\mathrm{h}=$ minasgerais|luminarias|infograficos:-informacoes-completas $>$ Acesso em: 13/02/2018.

JOLLIFFE, I. T.; CADIMA, J. Principal component analysis: a review and recent developments. Philosophical Transactions of The Royal Society A Mathematical Physical and Engineering Sciences, v. 374, n. 2065, p. 1-16, 2016.

KEMPTON, W. M.; BOSTER, J. S.; HARTLEY, J. A. Environmental values in American culture. Boston: MIT Press, 1995.

KRUGER, O. The Role of Ecotourism in Conservation: Panacea or Pandora's Box? Biodiversity and Conservation, v. 14, p. 579-600, 2005.

MANYARA, G.; JONES, E. Community-based tourism enterprises development in Kenya: An exploration of their potential as avenues of poverty reduction. Journal of Sustainable Tourism, v. 15, n. 6, p. 628-644, 2007.

MANZO, L. C.; PERKINS, D. D. Finding common ground: the importance of place attachment to community participation and planning. Journal of Planning Literature, 20(4), 335-350. 2006.

MARDIA, K.V.; KENT, J. T.;BIBBY, J. M. Multivariate Analysis. Academic Press. Minchin, P.R. (1987) An evaluation of relative robustness of techniques for ecological ordinations. Vegetatio, v. 69, p. 89-107, 1979.

MARUJO, N.; SANTOS, N. Turismo, Turistas e Paisagem. Investigaciones Turísticas, Espanha, n. 4, p.35-48, jul-dez, 2012.

MINCHIN, P.R. An evaluation of relative robustness of techniques for ecological ordinations. Vegetatio. v. 69, p. 89-107, 1987.

MINAYO, M. C. S.; DESLANDES, S. F.; GOMES, R. Pesquisa Social: Teoria, método e criatividade. Ed. Vozes. Petrópolis, RJ, 2016.

OKSANEN, J.; BLANCHET, F.J.; FRIENDLY, M.; KINDT, R.; LEGENDRE, P.; MCGLINN, D.; MINCHIN, P.R.; O'HARA, R.B.; SIMPSON, G.L.; SOLYMOS, P.; STEVENS, M.H.H.; SZOECS, E.; WAGNER, H. Vegan: community ecology 
package. R packageversion 2.4-2, 2017. Disponível em: <https://cran.rproject.org/package $=$ vegan $>$.

OKELLO, F. Ecotourism in Uganda a Case Study of The Mgahinga National Park. 2003. 64 p. M.Sc. Thesis (Tourism and Hospitality Management), Graduate Business, Göteborg University, Göteborg, 2003.

OTHMAN, N. A; ANWAR, A. M.; KIAN, L. L. Sustainability Analysis: Visitors Impact on Taman Negara, Pahang, Malaysia. Journal of Tourism, Hospitality \& Culinary Arts, v. 1, p.67-80, 2010.

PAKARINEN, N. Transition Practices: Education for Sustainable Development in Ecotourism. 2015. 31p. Master thesis (Sustainable Development), Department of Earth Sciences, Uppsala University, Sweden, 2015.

PAUW, J. B.D.; PETEGEM, P. V.A cross-cultural study of environmental values and their effect on the environmental behavior of children. Environment and Behavior, v. 45, p. 551-583, 2011.

PIRES, E. V.; ALCANTARINO, M. D. A participação das comunidades autóctones no turismo e o capital social no processo de desenvolvimento local: um exame do Programa Turismo Solidário - MG. Caderno Virtual de Turismo, v. 8, n 1, 2008.

POMERANZ, E. F.; NEEDHAM, M. D.; KRUGER, L. E. Stakeholder perceptions of indicators of tourism use and codes of conduct in a coastal protected area in Alaska. Tourism in Marine Environments, v. 9, p. 95-115, 2013.

R Studio version 3.3.1. 2016. "Bug in Your Hair" Copyright (C). The $\boldsymbol{R}$ Foundation for Statistical Computing Platform: i386-w64-mingw32/i386 (32bit). Disponível em: <http://wallace.teorekol.lu.se/statistics for biologists/01/R\%20output\%20ex1\% 20ht16.ppd>.

RAMOS, L. M. J.; OLIVEIRA, S. F. Educação ambiental para o ecoturismo nas unidades de conservação: um nexo ontológico. Revista Eletrônica do Mestrado em Educação Ambiental Revista do PPGEA/FURG-RS, v. 20, 2008.

RODRIGUES, L. A.; CARVALHO, D. A; OLIVEIRA FILHO, A. T.; CURI, N. Efeitos de solos e topografia sobre a distribuição de espécies arbóreas em um fragmento de floresta estacional Semidecidual, em Luminárias, MG. Revista Árvore, Viçosa, v. 31, p. 25-35 2007.

ROSS, S.; WALL, G. Ecotourism: Towards Congruence between Theory and Practice. Tourism Management. v. 20, p. 123-132, 1999.

SCHACTER, D. L.; GILBERT, D. T.; WEGNER, D. M. Psychology, 2nd edition.Worth. Publishers. p. 264, 2011.

SETUR. Secretaria de Estado de Turismo de Minas Gerais. Circuitos Turísticos e suas regiões. 2015. Disponível em: <http://www.turismo. mg.gov.br/circuitos-turisticos/informacoes-administrativas> Acessado em: 13/02/2018.

SIMÕES, P. F. P. F. A paisagem cultural do Buçaco: a singularidade de um território turístico e de lazer. Cadernos de Geografia, Coimbra, n. 32, p. 187193, 2013. 
SELIN, S. Natural resource partnerships: bridging practice and science. In: MANFREDO, M. J.; VASKE, J. J.; BRUYERE, B. L.; FIELD, D. R.; BROWN, P. J. (Eds.), Society and natural resources: A summary of knowledge, Jefferson, MO: Modern Litho, p. 137-146, 2004.

TSAUR, S. H.; LIN, Y. C.; LIN, J. H. Evaluating Ecotourism Sustainability from the Integrated Perspective of Resource, Community and Tourism. Tourism Management, v. 27, p. 640-653, 2006.

VARGAS, H. C. Turismo e valorização do lugar. Turismo em Análise, v.9, n.1, 1998.

VIOLIN, F. L.; ALVES, G. L. Da pesca ao natural: trajetória do turismo em Mato Grosso do Sul (1970 a 2015). Sustentabilidade em Debate - Brasília, v. 8, n. 2, p. 130-146, 2017.

WIGHT, P. A. Supporting the Principles of Sustainable Development. Journal Current Issues in Tourism, v. 5, p. 3-4, 2002

ZHANG, H.; LEI, S. L.A structural model of residents' intention to participate in ecotourism: The case of a wetland community. Tourism Management, v. 33, n. 4, p. 916-925, 2012.

Vinícius do Couto Carvalho: Universidade Federal de Lavras, Lavras, MG, Brasil.

E-mail: ecosdoturismo@gmail.com

Link para o currículo Lattes: http://lattes.cnpq.br/6275361882097842

Wanderley Jorge da Silveira Junior: Universidade Federal de Lavras, Lavras, MG, Brasil.

E-mail: jjjuniorjf@hotmail.com

Link para o currículo Lattes: http://lattes.cnpq.br/7083630018901697

Cléber Rodrigo de Souza: Universidade Federal de Lavras, Lavras, MG, Brasil. E-mail: crdesouza@hotmail.com

Link para o currículo Lattes: http://lattes.cnpq.br/1056892310025226

Thallita Mayra Soares Fernandes: Universidade Estadual do Rio de Janeiro, Rio de Janeiro, RJ, Brasil.

E-mail: thallitamsf@gmail.com

Link para o currículo Lattes: http://lattes.cnpq.br/7099650743935942

Marco Aurélio Leite Fontes: Universidade Federal de Lavras, Lavras, MG, Brasil.

E-mail: fontes@dcf.ufla.br

Link para o currículo Lattes: http://lattes.cnpq.br/6809021495935047

Data de submissão: 14 de junho de 2019

Data de recebimento de correções: 17 de setembro de 2019

Data do aceite: 17 de setembro de 2019

Avaliado anonimamente 